
\title{
25 Research Square \\ High-dose saccharin does not induce gut microbiota changes or glucose intolerance
}

Joan Serrano

Kathleen R. Smith

Audra L Crouch

Vandana Sharma

Fanchao Yi

Veronika Vargova

Traci E. LaMoia

Lydia M. Dupont

Vanida Serna

Fenfen Tang

Laisa Gomes-Dias

Joshua Blakeslee

Emmanuel Hatzakis

Scott N. Peterson

Matthew Anderson

Richard E. Pratley

George A. Kyriazi

\section{Video Byte}

Keywords: artificial sweeteners, saccharin, sweet taste receptors, gut microbiota, glucose intolerance, short-chain fatty acids, fecal metabolomics, T1R2, dysbiosis, Microbiome

Posted Date: March 11th, 2021

DOI: https://doi.org/10.21203/rs.3.rs-318775/v1

License: @ (i) This work is licensed under a Creative Commons Attribution 4.0 International License. Read Full License 


\section{Abstract}

Non-caloric artificial sweeteners (NCAS) are widely used as a substitute for dietary sugars to control body weight or glycemia. With a drastic increase in their use recently, health officials have been concerned about the effects of NCAS use. Epidemiological studies have had conflicting results, with some studies suggesting that NCAS can alter the gut microbiota or induce glucose intolerance. A new clinical study explored the effects of pure saccharin on the gut microbiota and glucose tolerance in healthy individuals. In a double-blind, placebo-controlled, parallel arm study involving men and women, researchers found that the maximum acceptable daily intake of saccharin, lactisole, or saccharin with lactisole did not alter microbial diversity or oral glucose tolerance. A parallel study with healthy mice had similar results, with no treatment altering microbial diversity, glucose absorption, or microbial activity. While further studies are needed to expand these findings to additional sweeteners, the results suggest that short-term saccharin consumption on its own does not alter gut microbiota or induce glucose intolerance in healthy humans and mice. Future studies should concentrate on identifying the underlying physiological or lifestyle conditions that may make artificial sweetener use harmful. 